\title{
Collateral and short squeezing of liquidity in fixed rate tenders
}

\author{
Nyborg, Kjell G ; Strebulaev, Ilya A
}

\begin{abstract}
The paper models fixed rate tenders, where a central bank offers to lend central bank funds to financial institutions. Bidders are constrained by the amount of collateral they have. We focus on the strategic interaction between bidding in the tender and trading in the interbank market after the tender, where short squeezes could occur. We examine how the design of the tender affects equilibrium bidding behavior and the incidence of short squeezes. Important elements in the analysis include the type of policy implemented by the central bank as well as bidders' initial endowments of liquidity and collateral. Three instruments for softening short squeezes are identified: the tender rate, the tender sizes, and admissible collateral. Increasing the tender rate or size tends to decrease the probability and severity of a short squeeze. The possibility of a short squeeze may induce bidders to oversubscribe even if the tender rate is higher than the competitive rate.
\end{abstract}

DOI: https://doi.org/10.1016/S0261-5606(01)00023-7

Posted at the Zurich Open Repository and Archive, University of Zurich

ZORA URL: https://doi.org/10.5167/uzh-110684

Journal Article

Accepted Version

Originally published at:

Nyborg, Kjell G; Strebulaev, Ilya A (2001). Collateral and short squeezing of liquidity in fixed rate tenders. Journal of International Money and Finance, 20(6):769-792.

DOI: https://doi.org/10.1016/S0261-5606(01)00023-7 


\title{
Collateral and Short Squeezing of Liquidity in Fixed Rate Tenders*
}

\author{
Kjell G. Nyborg ${ }^{\dagger} \quad$ Ilya A. Strebulaev ${ }^{\ddagger}$
}

This version: March 2001

Forthcoming Journal of International Money and Finance

${ }^{*}$ We would like to thank Francesco Cafagna, Laurent Clerc, Jürgen von Hagen, Philipp Hartmann, Mark Painting, and an anonymous referee for useful discussions and comments. We have also benefited from comments made by participants at the conference Central Bank Operations: Theory and Evidence (organized by ZEI and the Bundesbank, September 2000). The usual disclaimer applies.

${ }^{\dagger}$ London Business School and CEPR, Regent’s Park, London NW1 4SA, UK, knyborg@london.edu

‡London Business School, Regent’s Park, London NW1 4SA, UK, istrebulaev@london.edu 


\title{
Collateral and Short Squeezing of Liquidity in Fixed Rate Tenders
}

\begin{abstract}
The paper models fixed rate tenders, where a central bank offers to lend central bank funds to financial institutions. Bidders are constrained by the amount of collateral they have. We focus on the strategic interaction between bidding in the tender and trading in the interbank market after the tender, where short squeezes could occur. We examine how the design of the tender affects equilibrium bidding behavior and the incidence of short squeezes. Important elements in the analysis include the type of policy implemented by the central bank as well as bidders' initial endowments of liquidity and collateral. Three instruments for softening short squeezes are identified: the tender rate, the tender size, and admissible collateral. Increasing the tender rate or size tends to decrease the probability and severity of a short squeeze. The possibility of a short squeeze may induce bidders to oversubscribe even if the tender rate is higher than the competitive rate.
\end{abstract}

Keywords: short squeeze, collateral, fixed rate tender, liquidity

JEL index: D44, E58, G28 


\section{Introduction}

The fixed rate tender is seemingly one of the simplest, but also most important, mechanisms for distributing large quantities of a homogeneous good among multiple agents. For example, fixed rate tenders have for a long time played an important role in the money markets. The Bundesbank introduced fixed rate tenders in the 1980's as their main vehicle for distributing DM denominated funds to the banking sector. This mechanism was also initially adopted by the European Central Bank (ECB) for its main refinancing operations. In a fixed rate tender, a lender announces a rate at which he is willing to lend money of a given maturity, and borrowers respond by simultaneously submitting bids for how much they would like to borrow at the announced rate. Any excess demand is usually allocated pro rata. In this paper, we study the strategic interaction between bidding in the tender and trading in the interbank market after the tender. Despite the simple structure of the tender, we find that strategic behavior in the secondary market affects equilibrium behavior in the tender in a profound way.

The strategic issue we focus on is that some banks face a liquidity shortfall, and if they fail to cover this in the tender, they must go to the interbank market, where they can be charged very high rates by other banks that are long liquidity. In other words, we examine how a potential short squeeze impacts on bidding in the tender. That a squeeze on liquidity can occur from time to time is suggested by the spikes observed in interbank rates around the end of the reserve maintenance period (see e.g. Hamilton (1996) for US and Biais, Hartmann, and Manna (2000) for European evidence). We also examine how the design of the tender affects the incidence of short squeezes. Our analysis identifies three main instruments in a fixed rate tender that a central bank can use to control the incidence of a short squeeze. These are: the tender rate, the tender size, and admissible collateral.

Although our paper is cast in the context of the money markets, our analysis can easily be translated into a situation where bidders compete to buy (rather than borrow) the underlying asset. For example, fixed price offers are widely used in IPO's. However, apart from the possibility of a short squeeze, the other important ingredient in our analysis is something which has particular relevance in the money markets; namely, collateral. ${ }^{1}$

An important feature of fixed rate tenders of central bank funds is that collateral is required to participate. In particular, in return for the funds it obtains in the tender, a financial institution must hand over collateral to the central bank, which is returned when the loan is repaid. In short, the transaction is a repurchase agreement (repo). This means that individual banks are constrained in how much they can borrow in the tender by the collateral that they have.

The possibility of a short squeeze in the interbank market after the tender has important implications for the bidders in the tender as well as for the central bank. Bidders are interested in knowing how much to demand in order to avoid being squeezed, if short, or

\footnotetext{
${ }^{1}$ The fixed price offer IPO literature focuses on very different issues than what we do here; for example, Rock (1986), using a fixed price offer model, explains that new issues can be underpriced as a result of private information among potential buyers. Collateral has been discussed in other settings, for example, by Bester (1987 and 1994) and Holmstrom and Tirole (1997).
} 
attempt to implement a squeeze, if long. From a central bank's perspective, the point of a tender is to channel liquidity to individual financial institutions that need it. But if the funds get concentrated in non-needy hands, this job is taken away from the primary markets and handed over to the secondary market. That in itself may be undesirable since trading is generally costly. But more importantly, it can lead to a short squeeze, where the borrowing rate for banks with a liquidity shortfall becomes very high - and higher than the central bank may have intended. This distortion of the interbank rate away from the competitive rate can also feed back to commercial borrowing rates, for example, making them unusually high. For these reasons, a central bank may be interested in knowing how to design a tender so as to minimize the incidence of short squeezes.

We study these issues in a model of a fixed rate tender of collateralized borrowing where initially some bidders are short while others are long. Bidders who fail to cover their short positions in the tender must do so in the interbank market after the tender, where they may be squeezed. At this stage, the model draws on the literature on short squeezes. ${ }^{2}$ However, the main emphasis in our paper is on the tender itself and on how bidding in the tender is affected by a potential short squeeze. Related work include Chatterjea and Jarrow (1998) and Nyborg and Strebulaev (2001), who study different primary market mechanisms than what we do here. Like us, Catalao-Lopes (2000) also studies a fixed rate tender and an interbank market, but unlike us, she does not explicitly model short squeezes. In our model, the interbank rate may vary according to whether or not a squeeze is on.

Our model accommodates both the cases where the tender rate is above and below the competitive secondary market rate. The former scenario can happen in practice if, for example, interest rate expectations are rising or the central bank is running a loose monetary policy. We first show that if the tender rate is below the competitive rate, banks demand as much as their collateral allows them to in the tender. As a result, the tender generally will be oversubscribed and there will be a relatively high incidence of short squeezes. But our most interesting findings concern the case where the tender rate is above the competitive rate. In this case, bidders may nevertheless demand positive amounts in the tender because of the possibility of a short squeeze. However, we also show that increasing the tender rate or tender size tends to result in a lower total demand and a lower incidence of short squeezes. Intuitively, increasing the tender rate or tender size tends to increase the costs of implementing a short squeeze, eventually leading long players to stop participating in the tender. A general result that emerges from our analysis is that tenders that are oversubscribed also tend to be followed by short squeezes. Moreover, the interbank rate tends to be more volatile in the event of a short squeeze than otherwise. Finally, we show that reducing the securities that are admissible as collateral in the repos may reduce the incidence of short squeezes.

While our model gives rise to pure strategy equilibria in many cases, under some conditions when the tender rate is "intermediate," only mixed strategy equilibria exist, where bidders randomize over a set of quantities to demand in the tender. In this case, it is uncertain whether or not there will be a short squeeeze in equilibrium and whether or

\footnotetext{
${ }^{2}$ Models of market cornering and short squeezes include: Cooper and Donaldson (1998), Jarrow (1992 and 1994), and Kumar and Seppi (1992).
} 
not the tender will be under or oversubscribed. This is quite surprising since there is no private information in our model.

The rest of the paper is organized as follows. Section 2 describes the model. Section 3 analyses the case that the tender rate is below the competitive rate, Section 4 analyses the case that the tender rate is above the competitive rate. Section 5 contains a discussion of various ways to extend the model as well as some concluding remarks. An appendix contains proofs not supplied in the text.

\section{The Model}

We study a discrete time model, where the focus is on events which take place within a single day. In particular, early in the day, at time 1, there is a fixed rate tender for repos with a central bank. Later in the day, at time 2, the tender results are announced and the interbank money market opens. Players that started the day with short positions must cover their positions by the end of the day. This opens up the possibility of short squeezing. Finally, all repos and loans mature at a future day, time 3. Players seek to maximize their interest earnings (minimize interest costs) at time 3.

There are two players, whom we shall call the short and the long, $S$ and $L$ respectively. These names will be clear from the description below. ${ }^{3}$ We think of these players as representing commercial banks or some other financial institutions. They are the only counterparties to the central bank in the fixed rate tender and can trade between themselves after the tender. The two banks start the day with initial endowments of central bank funds of $y_{S}$ and $y_{L}$, where $Y \equiv y_{S}+y_{L}>0$. These endowments are exogenous in the model; they could have been established from the banks' normal day-to-day activities in various money and securities markets. Furthermore, we assume that $y_{S}<0$ and $y_{L}>0$. This means that the short is short of liquidity at the beginning of the tender day; whereas, the long has a positive amount of liquidity. If the short does not succeed in obtaining sufficient money in the tender to cover his position, he will have to borrow it from the long in the secondary market at time 2. If the short obtains nothing in the tender, he will therefore have to borrow $z_{0} \equiv\left|y_{S}\right|$ units from the long.

To do a repo with the central bank, financial institutions need collateral. We assume that the short and long have positive initial endowments of collateral of $c_{S}$ and $c_{L}$, respectively. In real markets it is usually the case that different types of collateral exist (due to differences in maturity, issuer, the consequences and possibility of default, specialness, haircuts, etc); we abstract from that here and assume that there is only one type of general collateral.

At time 1, the central bank holds a fixed rate tender, where it offers the market participants $Q \leq c_{S}+c_{L}$ (divisible) units of money, which matures at date 3 and carries an interest rate of $R_{T}$. The tender rate, $R_{T}$, is somewhere between $R_{L}$ and $R_{H}$, where $R_{L}$ and $R_{H}$ are the overnight deposit standing facility rate and overnight lending standing

\footnotetext{
${ }^{3}$ By having more players, we would add complexity to the model, but this would not change our main conclusions regarding the conflict betweeen short and long players. Nyborg and Strebulaev (2001) develop a model with multiple players, but where the primary market is organized as a uniform or discriminatory price auction.
} 
facility rate of the central bank, respectively. ${ }^{4}$ Banks may submit bids in the tender, specifying non-negative quantities $b_{S} \leq c_{S}$ and $b_{L} \leq c_{L}$, for the short and long respectively. The upper bounds on the bids capture the collateralized nature of the tender allocations. ${ }^{5}$ Formally, the tender is an offer to do repos with the central bank. This means that to obtain $q$ units of central bank funds, a player must hand over collateral to the central bank which he then can repurchase at time 3 for $q\left(1+R_{T}\right)$. We do not model the repurchase decision at time 3 , but assume that banks always do so, since otherwise they lose the collateral. In practice, the amount of central bank funds one can obtain with a particular collateral is usually set so as to ensure that the collateral will be repurchased. Finally, bids in the tender are pro-rata rationed if total demand exceeds $Q$, otherwise bidders receive what they demand. That is, bank $i$ is allocated

$$
q_{i}=\min \left[\frac{b_{i}}{b_{S}+b_{L}} Q, b_{i}\right], i=S, L .
$$

So after the tender, the total position of money of each of the two banks are: $m_{i}=y_{i}+q_{i}$, $i=S, L$.

At time 2, if the positions of both players are positive, they simply lend their funds to other institutions or commercial enterprises at the market rate of $R_{0} \in\left(R_{L}, R_{H}\right)$. If, however, $m_{S}<0$, we need a model of how the short covers his position in the secondary market. We model this as a delivery game between the short, the long, and the central bank; following Cooper and Donaldson (1998). ${ }^{6}$ Since money is in positive supply, the long has sufficient funds to provide what the short needs. In particular this means that the long posts a lending rate for $z_{2} \equiv\left|\min \left[0, m_{S}\right]\right|$ units of money. ${ }^{7}$ The short then could choose either to borrow from the long or from the central bank. Once the short has covered his position, the long can lend any cash on hand at the competitive rate, $R_{0}$. It is clear that the long optimizes by asking $R_{H}$ (or marginally below this). As a result, in equilibrium, the long squeezes the short on $z_{2}$ units. So $z_{2}$ could be viewed as a measure of the long's market power at time 2. Similarly, if no tender were held, we could think of $z_{0}=\left|y_{S}\right|$ as the initial market power of the long. An important objective of the short and possibly of the auctioneer is to get this market power reduced in the tender.

Hence, time 3 interest earnings/payments are given by:

$$
\pi_{S}= \begin{cases}R_{0}\left(y_{S}+q_{S}\right)-R_{T} q_{S} & \text { if } z_{2}=0 \\ R_{H}\left(y_{S}+q_{S}\right)-R_{T} q_{S} & \text { if } z_{2}>0\end{cases}
$$

\footnotetext{
${ }^{4} R_{H}-R_{L}$ is the Central Bank discount window. The European Central Bank usually sets the tender rate in the middle of the window.

${ }^{5}$ We discuss the possibility that banks can bid for more than what they have collateral for in the concluding section of the paper.

${ }^{6}$ The thrust of our arguments regarding the linkage between the secondary and primary markets would go through for any other model of how the short covers his position in the secondary market, provided that the long has an opportunity to exercise his market power. The way we have chosen to model this is attractive because of its simplicity, which allows us to concentrate our efforts on bidder behavior in the tender. For a description of the secondary money market in the European system see Biais, Hartmann, and Manna (2000).

${ }^{7}$ Cooper and Donaldson (1998) describe the procedure as a sequential delivery game where the number of rounds equals the number of units the short is squeezed on. We use more simple structure since we have only 2 players.
} 
for the short, and

$$
\pi_{L}= \begin{cases}R_{0}\left(y_{L}+q_{L}\right)-R_{T} q_{L} & \text { if } z_{2}=0 \\ R_{H} z_{2}+R_{0}\left(m_{L}-z_{2}\right)-R_{T} q_{L} & \text { if } z_{2}>0\end{cases}
$$

for the long. We now turn to analyzing how players bid in the tender to maximize these payoffs.

\section{$3 \quad$ Loose Monetary Policy}

One of the main instruments of the monetary policy of a central bank is the target interest rate. In this paper we study the case that the central bank injects liquidity into the market via a fixed rate tender. So the target rate is simply the tender rate, $R_{T}$. If monetary policy is restrictive or interest rate expectations are falling, then $R_{T}>R_{0}$. When it is loose or interest rate expectations are rising, $R_{T} \leq R_{0}$. In this paper, we take the tender rate as given and ask how banks that are short or long of liquidity bid in the tender. Moreover, we ask how the equilibrium bidder behavior impacts on the incidence of short squeezes. It turns out that bidder behavior is dramatically different under a loose and tight monetary policy. We consider these two cases separately, first focusing on the tender under a loose monetary policy.

In this section, we assume that $R_{T} \leq R_{0}$. Hence, the tender affords banks with an arbitrage opportunity, and so all banks will demand as much as their collateral allows them to in the tender. ${ }^{8}$ In this case, player $i$ receives an allotment of $\lambda c_{i}$ where $\lambda$ is the allotment rate under "full participation," i.e., $\lambda=\frac{Q}{c_{S}+c_{L}}$. Here, whether or not a short squeeze will occur is therefore a simple function of initial positions, the size of the short and long's collateral, and the tender size.

Theorem 1 Suppose, that monetary policy is loose (i.e. $R_{T} \leq R_{0}$ ). The optimal strategy for each player in the tender is to demand a quantity equal to the size of his collateral. In this unique equilibrium, there is a short squeeze if and only if $z_{0}>\lambda c_{S}$. Equilibrium payoffs are given by

$$
\pi_{i}= \begin{cases}y_{i} R_{0}+\lambda c_{i}\left(R_{0}-R_{T}\right) & \text { if } i=S, L \text { and } z_{0} \leq \lambda c_{S} \\ \left(y_{S}+\lambda c_{S}\right) R_{H}-\lambda c_{S} R_{T} & \text { if } i=S \text { and } z_{0}>\lambda c_{S} . \\ \left(z_{0}-\lambda c_{S}\right) R_{H}+\left(y_{L}-z_{0}+Q\right) R_{0}-\lambda c_{L} R_{T} & \text { if } i=L \text { and } z_{0}>\lambda c_{S} .\end{cases}
$$

An immediate implication of this Theorem is that when monetary policy is loose, the size of a short squeeze is $(i)$ decreasing in the collateral of the short, $(i i)$ decreasing in the tender size, and ( $i i i)$ increasing in collateral of the long. Furthermore, it is possible to avoid short squeezes in the secondary market altogether by choosing a sufficiently large tender size. A drawback with such a policy, however, is that it is likely to result in the central bank ending up flooding the market with cheap liquidity. The general message that

\footnotetext{
${ }^{8}$ Such an arbitrage opportunity could in reality exist for a long period of time. During the period when the European Central Bank held fixed rate tenders in 1999-2000, the corresponding interbank market rate (collateralized with the same maturity) was very often higher than the fixed rate target of the ECB.
} 
emerges is thus that when the central bank wishes to follow a loose monetary policy, the fixed rate tender may not be the best mechanism for injecting liquidity into the markets and leads to strong overbidding. This may help explain why the ECB changed its repo auctions from fixed rate tenders to a variable rate tenders in June 2000, since the early part of 2000 was a period of rising interest rate expectations. See Breitung and Nautz (2000) for an empirical analysis of the ECB's fixed rate tender experience and Ehrhart (2000) for an experimental investigation of fixed rate tenders.

\section{Tight Monetary Policy}

In this section, we study the fixed rate tender in the case that monetary policy is tight, i.e., $R_{T} \in\left(R_{0}, R_{H}\right)$. The analysis here is more complex than in the case of a loose monetary policy, since now the players cannot exploit arbitrage opportunities between the primary and secondary markets. Instead, the high tender rate now creates a potential disincentive to buy in the tender. The short will nevertheless always demand a positive amount, in an attempt to avoid being squeezed or reduce the units on which he may be squeezed. Every unit he is allocated in the tender gives him a saving of $R_{H}-R_{T}$. So the short will demand at least $z_{0}$ units, if he has sufficient collateral to do so. But exactly how much the short will demand depends on what the long demands, and vice versa.

The equilibrium outcome turns out to depend upon the relation between the short's initial position, the short and long's collateral, the tender size, and the tender rate. As a guide to the analysis that follows, we first provide an overview of the main cases.

1. The short cannot cover his position regardless of how the long bids. This is the case if the tender is too small or the short's collateral is too small, i.e., if $z_{0}>\min \left(Q, c_{S}\right)$.

2. It is possible for the short to cover his position. This requires $z_{0}<\min \left(Q, c_{S}\right)$. There are a number of important subcases.

(a) The short can cover his position regardless of the long's strategy by demanding $z_{0}$ in the tender. In other words, the short does not face competition from the long for the $z_{0}$ units he needs to cover. This is the case if tender size is relatively large (or the long's collateral is relatively small), i.e., if $z_{0}+c_{L}<Q$.

(b) The short can cover his position regardless of the long's strategy by demanding $c_{S}$ in the tender. This is the case if the short's collateral is relatively large, i.e., $\lambda c_{S} \geq z_{0}$. An intriguing aspect of this case is that although the short has it within his grasp to cover his position in the tender, he may not wish to do so with certainty - since it may involve getting more units than he strictly speaking needs. After the first $z_{0}$ units, every unit that the short obtains gives him a loss of $R_{T}-R_{0}$.

(c) The short cannot cover his position if the long demands $c_{L}$. This is the case if the short's collateral is relatively small, i.e., $\lambda c_{S}<z_{0}$. In this case, if the long's strategy is to demand $c_{L}$ in the tender, then the short would obviously wish to demand $c_{S}$, since that minimizes the number of units that he will be short after 
the tender. But it is not at all clear that the long will wish to demand $c_{L}$ in the first place, since the interest rate may be so high as to not make it worthwhile for the long to try to implement a squeeze.

We now turn to examining equilibrium behavior in these cases.

\subsection{The Short Cannot Cover}

In this subsection, we assume that $z_{0}>\min \left(Q, c_{S}\right)$, implying that it is impossible for the short to cover his position in the tender. We first consider the case that the tender is too small for the short to be able to cover (i.e., $Q \leq z_{0}$ ), and second the case that the short's collateral is too small (i.e., $c_{S} \leq z_{0} \leq Q$ )

Theorem 2 Suppose (i) monetary policy is tight (ii) and the tender size is too small for the short to cover. ${ }^{9}$ In the unique equilibrium: (a) each player demands a quantity equal to his collateral; (b) the tender is oversubscribed and there is always a short squeeze in the secondary market; and (c) the players' payoffs are:

$$
\pi_{i}= \begin{cases}-z_{0} R_{H}+\lambda c_{S}\left(R_{H}-R_{T}\right) & \text { if } i=S \\ y_{L} R_{0}+\left(R_{H}-R_{0}\right)\left(z_{0}-Q\right)+\left(R_{H}-R_{T}\right) \lambda c_{L} & \text { if } i=L\end{cases}
$$

\section{Proof of Theorem 2}

Since $z_{0} \geq Q$, when both players demand positive quantities in the tender, both players will receive positive allotments and the short's allotment will be less than $z_{0}$. Moreover, every unit won by the long can be lent to the short at $R_{H}$ in the secondary market. Since $R_{T}<R_{H}$, it follows that both bidders will demand as much as their collateral allows them to. Hence the short receives an allotment of $\lambda c_{S}$ and the long receives an allotment of $\lambda c_{L}$. Hence, the short will have a short position of $z_{0}-\lambda c_{S}$ after the tender. The Theorem follows by observing that, on this amount, the long earns (and the short pays) and interest rate $R_{H}$. Moreover, both pay $R_{T}$ on what they obtain in the tender, and the long earns $R_{0}$ on $y_{L}+Q-z_{0}$ units.

The most interesting aspect of this result is perhaps that the tender can be oversubscribed even though the tender rate is above the competitive rate. The intuition is clear: since there will be a squeeze for sure in the secondary market, both players are rushing to buy in the tender. This oversubscription result is, as we shall see, a fairly general implication of a potential short squeeze in the post-tender market (but an exception to this is found in the next theorem). The result that players demand amounts equal to their collateral for any tender rate below $R_{H}$ is, however, more specific to the case of small tenders.

Theorem 3 Suppose (i) monetary policy is tight (ii) and the short's collateral is too small for the short to cover. ${ }^{10}$ There is a participation ceiling, $\theta_{c}=R_{0}+\frac{\left(R_{H}-R_{0}\right)\left(c_{S}+c_{L}-Q\right)}{Q}$, such that: (a) If $R_{T}<\theta_{c}$, the unique equilibrium is for both players to demand quantities equal to their collateral in the tender. In this case, the tender is oversubscribed and there is a

\footnotetext{
${ }^{9}$ By these statements we mean: (i) $R_{T} \in\left(R_{0}, R_{H}\right]$ and (ii) $z_{0} \geq Q$.

${ }^{10}$ By these statements we mean: (i) $R_{T} \in\left(R_{0}, R_{H}\right]$ and (ii) $c_{S} \leq z_{0} \leq Q$.
} 
short squeeze in the secondary market. (b) $R_{T}>\theta_{c}$, the short demands an amount equal to his collateral in the tender, and the long demands nothing. In this case, the tender is undersubscribed and there is a short squeeze in the secondary market. The unique equilibrium payoffs are:

$$
\pi_{i}= \begin{cases}\left(y_{L}-z_{0}+c_{S}\right) R_{0}+\left(z_{0}-c_{S}\right) R_{H} & \text { if } i=L \text { and } R_{T} \geq \theta_{c} \\ -\lambda c_{L} R_{T}+\left(z_{0}-\lambda c_{S}\right) R_{H}+\left(y_{L}+Q-z_{0}\right) R_{0} & \text { if } i=L \text { and } R_{T}<\theta_{c} \\ -c_{S} R_{T}-\left(z_{0}-c_{S}\right) R_{H} & \text { if } i=S \text { and } R_{T} \geq \theta_{c} \\ -\lambda c_{S} R_{T}-\left(z_{0}-\lambda c_{S}\right) R_{H} & \text { if } i=S \text { and } R_{T}<\theta_{c}\end{cases}
$$

\section{Proof of Theorem 3}

Given $c_{S} \leq z_{0}$ and $R_{T}<R_{H}$, it is a dominating strategy for the short to bid $c_{S}$, since this minimizes his short position in the post-tender market. It follows that the long either bids 0 or $b_{L}$ for which $c_{S}+b_{L}>Q$. For if $b_{L}+c_{S} \leq Q$, the long gets to squeeze on only $z_{0}-c_{S}$, implying the long would do better by bidding 0 , since $R_{T}>R_{0}$. Consider next that $b_{L}+c_{S}>Q$. The long's payoff is then given by

$$
\pi_{L}^{*}\left(b_{L}\right)=\left(z_{0}-\frac{c_{S}}{c_{S}+b_{L}} Q\right) R_{H}+\left(y_{L}-z_{0}+Q\right) R_{0}-\frac{b_{L}}{c_{S}+b_{L}} Q R_{T} .
$$

Note that

$$
\frac{\partial \pi_{L}^{*}}{\partial b_{L}}=\frac{c_{S} Q\left(R_{H}-R_{T}\right)}{\left(b_{L}+c_{S}\right)^{2}},
$$

so the payoff reaches a maximum only at the boundaries, 0 or $c_{L}$. The long's payoff from bidding 0 is

$$
\pi_{L}^{P}=\left(y_{L}-z_{0}+c_{S}\right) R_{0}+\left(z_{0}-c_{S}\right) R_{H}
$$

Now, since

$$
\pi_{L}^{*}\left(c_{L}\right)-\pi_{L}^{P}=\frac{1}{c_{S}+c_{L}}\left(\left(R_{H}-R_{0}\right)\left(c_{S}+c_{L}\right) c_{S}-Q\left(c_{S}\left(R_{H}-R_{0}\right)+c_{L}\left(R_{T}-R_{0}\right)\right)\right),
$$

it follows that there is $\theta_{c}$ such that the long bids $c_{L}$ if $R_{T}<\theta_{c}$ and 0 otherwise. $\theta_{c}$ is such that equalizes the right hand side of the above expression to 0. Moreover, simple algebra confirms that $\theta_{c}$ is as stated in the Theorem. Further algebra confirms that payoffs are as stated. Finally, when $\theta_{c} \neq R_{T}$, the equilibrium we have described is unique since the short makes his decision to bid $c_{S}$ without taking into account the strategy of the long. (When $\theta_{c}=R_{T}$, the long may mix between 0 and $c_{L}$. Payoffs, however, are identical.)

Taken together, Theorems 2 and 3 give all equilibria in the case that the short cannot possibly cover in the tender, either because the tender size is too small or the short's collateral is too small. The two Theorems also reveal that the long's behavior is significantly different under the two constraints on the short's ability to cover. Specifically, when the constraint on the short is that the tender is too small, the long always bids $c_{L}$, since this maximizes the quantity on which he can squeeze. But when the tender size is large enough for the short to cover, but the short does not have sufficient collateral to do so, the long 
stops participaing when the tender rate goes above some ceiling. This contrast is easily explained. When $Q<z_{0}$, the long gets to squeeze on every unit he buys. Therefore, he tries to buy as many units as possible provided that the tender rate is below the "squeeze rate", $R_{H}$. In contrast, when $Q>z_{0}$, the long does not get to squeeze on every unit he buys. Hence, he faces a tradeoff in the tender between quantity and interest costs. This tradeoff gives rise to the participation ceiling we see in Theorem 3 .

As a further implication of Theorems 2 and 3, we have the following empirical predictions:

Proposition 1 Let $c_{S}<z_{0}$ and $R_{T} \in\left(R_{0}, R_{H}\right)$ be given. In equilibrium: (1) The total quantity demanded in the tender, as well as the quantity demanded by the long in the tender, is increasing in the long's collateral and decreasing in the tender size. (2) The size of a squeeze in the secondary market is increasing in the long's collateral and decreasing in the tender size.

This proposition has an important policy implication. In particular, if a short squeeze is viewed as undesirable by the central bank, but the short player has insufficient collateral to cover his position, the central bank can minimize the size of a squeeze by making the tender "large." In practice, the size of a central bank repo tender is based upon the central bank's estimate of liquidity needs among financial institutions. Our analysis shows that if collateral shortfall is a concern, the central bank does better by erring on the side of holding a tender which is too large rather than erring on the side of holding a tender which is too small. Excess liquidity will not necessarily get into the market since long bidders may abstain from participating in the tender. The central bank can also decrease the size of a squeeze by choosing a high tender rate, along with a reasonably large tender size. However, the higher the tender rate, the more will the short have to pay to cover, something which may filter back to the banking markets with undesirable effects prior to the tender. So while our analysis here points out two primary "instruments" available to the central bank in a fixed rate tender in order to reduce the incidence of a short squeeze namely the tender rate and size - our analysis also shows that distortions can be minimized by choosing the tender size as large as possible. One caveat to this conclusion is that the analysis presumes that the short does not have sufficient collateral to cover. This is relaxed below.

\subsection{It Is Possible for the Short to Cover}

In this subsection, we assume that $z_{0}<\min \left(Q, c_{S}\right)$, implying that it is possible for the short to cover his position in the tender. We will discuss how the tender size, tender rate, and size of collateral impacts on equilibrium behavior, the bid-to-cover, and the incidence of short squeezes.

We start with the simplest of the three cases that we outlined at the beginning of this section; namely, the case that the tender size is so large that the short is guaranteed to cover by simply demanding what he needs. 
Theorem 4 Suppose (i) monetary policy is tight, (ii) it is possible for the short to cover, (iii) and the tender is not competitive. ${ }^{11}$ In the unique equilibrium: (a) In the tender, the short demands his liquidity shortfall, $z_{0}$, and the long demands nothing; (b) The tender is undersubscribed and there is no short squeeze in the secondary market.

This supports the result from the previous subsection that the incidence of short squeezes can be reduced by making the tender sufficiently large. In the case considered here, squeezes are eliminated since the short has sufficient collateral to cover and since the long has insufficient collateral to implement a squeeze. Theorem 4 also emphasizes the point that when the tender is large enough to allow the short to cover, a short squeeze can only occur if there is rationing in the tender. In other words, for the long to implement a short squeeze, he must have sufficient collateral, and bid enough of it, to induce rationing.

In the remainder of this section, we assume that $z_{0}+c_{L}>Q$. In the context of the ECB's fixed rate repo tenders, this is probably the most realistic scenario, due to the tender size being based on the ECB's estimate of banks' liquidity needs. Translating this into our model, this means that the tender size would be expected to be somewhat larger than $z_{0}$ - it should be around $z_{0}$ to cover immediate liquidity needs plus some amount to cover liquidity needs between the current tender and the next. When $z_{0}+c_{L}>Q$ and the short demands only $z_{0}$ units in the tender, the long can implement a squeeze by demanding $c_{L}$ units in the tender. But in that case, the short may wish to increase the number of units he asks for. The general point here is that the short's optimal demand in the tender now depends upon the number of units the long asks for. In other words, the tender is competitive.

An important result in the previous subsection was the existence of a participation ceiling such that if the tender rate is set above that ceiling, the long drops out of the tender. A similar result applies in the current setting.

Theorem 5 Suppose (i) monetary policy is tight, (ii) it is possible for the short to cover his position in the tender, and (iii) the tender is competitive. ${ }^{12}$ There is a participation ceiling, $\theta \in\left(R_{0}, R_{H}\right)$, such that if the tender rate is above the participation ceiling, the unique equilibrium is for the long to ask for zero units and for the short to ask for just enough units to cover his liquidity shortfall, $z_{0}$. In this case, the tender is undersubscribed and there are no short squeezes in the secondary market.

When the tender rate is above the competitive rate, the only reason for the long to participate in the tender is in order to try to implement a short squeeze. But when the tender size exceeds the number of units the short needs to cover, the long can only earn $R_{H}$ on a fraction of the units he obtains in the tender, since the short will always demand at least $z_{0}$ units in the tender. So when the tender rate goes above the participation ceiling, $\theta$, it simply does not "pay" for the long to try to implement a short squeeze. The proof of Theorem 5 shows that the participation ceiling $\theta$ is given by

$$
\theta=\frac{R_{0}\left(Q-z_{0}\right)+z_{0} R_{H}}{Q}-\frac{z_{0}}{c_{L} Q}\left(R_{H}-R_{0}\right)\left(Q-z_{0}\right)
$$

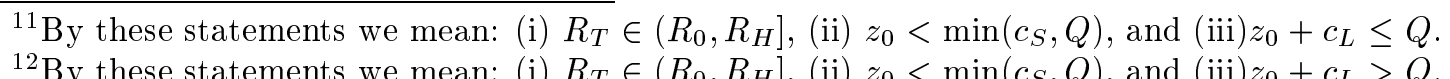


This implies:

Proposition 2 The participation ceiling $\theta$ is: (1) increasing in the long's collateral, $c_{L}$; (2) increasing in the liquidity shortfall, $z_{0}$; and (3) decreasing in the tender size $Q$.

The existence of a participation ceiling for the long shows that by setting the tender rate sufficiently high, the central bank can make sure that a short squeeze does not happen. Moreover, as shown in Proposition 2, the participation ceiling can be reduced by increasing the tender size. Intuitively, when the tender size is large it becomes more expensive for the long to implement a squeeze. When both the long and the short bid for quantities equal to their respective collaterals in the tender, the allotment of the long is increasing in the tender size. Hence, as the tender size increases, the long wins more and more units at the relatively high rate of $R_{T}$ which he can lend in the secondary market at only $R_{0}$. This makes it less attractive for the long to try to implement a squeeze when the tender size is large. An implication is that as the tender rate is approaching the competitive rate (from above), one way for the central bank to guarantee that there will be no squeeze in the secondary market is to increase the tender size.

Proposition 2 also shows that the participation ceiling is a function of the long's collateral and the short's liquidity shortfall. Specifically, the participation ceiling can be reduced by reducing the long's collateral. It is also increasing in the short's liquidity shortfall. Now, as the quantity of the collateral held by the long increases, he generally finds it more profitable to bid aggressively in the tender. For example, if the long does not face any collateral constraint, i.e., $c_{L} \rightarrow \infty$, the participation ceiling becomes

$$
\theta_{\infty}=\frac{z_{0} R_{H}+\left(Q-z_{0}\right) R_{0}}{Q}
$$

This value has a very simple and economically intuitive interpretation. Because the long does not face any collateral constraint, he will be allocated the full tender size if he chooses to participate fully. On the first $z_{0}$ units allocated the long obtains a rate of $R_{H}$ in the secondary market; while on the remainding $Q-z_{0}$ units, he obtains only $R_{0}$. The average of these lending rates is exactly equal to $\theta_{\infty} \cdot{ }^{13}$ It also means that the long will never participate in the tender, if $R_{T}>\theta_{\infty}$, no matter what collateral he has.

This result implies a general and fundamental observation, namely that introducing a collateral constraint in the tender leads to a reduction in the willingness of a to-beshort-squeezer to corner the market. The central bank has some power over the collateral since, for instance, it can change the allowable sets of collateral to try to reduce the relative quantities of collateral held by institutions that are long in liquidity. This policy has, however, a substantial drawback, since the central bank needs to know the initial positions in liquidity and collateral of all bidders, which is unlikely to be plausible.

To complete the analysis, we now ask the question: how do bidders bid when the tender rate is below the participation ceiling? We show below that the long will participate in the tender with positive probability and, as a result, there will be a short squeeze with positive probability. Interestingly, this probability is not generally equal to one.

\footnotetext{
${ }^{13}$ Nyborg and Strebulaev (2001) show that $\theta_{\infty}$ also plays a similar threshold role in case of discriminatory
} price, multiple unit auctions. 
Lemma 1 Suppose (i) monetary policy is tight but the tender rate is below the long's participation ceiling, $\theta$, (ii) it is possible for the short to cover his position in the tender, (iii) the tender is competitive. ${ }^{14}$ There is $\gamma \in\left(R_{0}, \theta\right)$ such that there is no pure strategy equilibrium if $R_{T} \in(\gamma, \theta)$. However, there are mixed strategy equilibria.

This Lemma is more than a technical result. In particular, it implies that in any equilibrium under the conditions of the lemma, a short squeeze happens with positive probability. Moreover, it shows that this probability can be less than 1 . The proof of the Lemma shows that $\gamma$ is given by

$$
\gamma= \begin{cases}\frac{R_{0}\left(Q-z_{0}\right)+z_{0} R_{H}}{Q}-\frac{c_{S}}{c_{L} Q}\left(R_{H}-R_{0}\right)\left(Q-z_{0}\right) & \text { if } z_{0}>\lambda c_{S} \\ R_{0} & \text { otherwise. }\end{cases}
$$

Comparing this with (6) confirms that $\gamma$ is always less than the participation ceiling, $\theta$, since in this section we are working under the assumption that the short has sufficient collateral to cover in the tender. Moreover, we see that there are two cases: (1) $z_{0}>\lambda c_{S}$ and (2) $z_{0} \leq \lambda c_{S}$. The first case means that the short cannot be guaranteed to cover by bidding all his collateral, because the short's collateral is simply too small relative to the tender size and the long's collateral. We think of this condition as representing the case of a small bank (a bank with relatively little collateral). The second case means that the short has so much collateral that he can definitely cover if he bids all his collateral in the tender. We think of this as representing the case of a large bank.

The expression for $\gamma$ shows that when the short is a relatively large bank, there are no pure strategy equilibria for any tender rate below the participation ceiling. In contrast, when the short is a relatively small bank, pure strategy equilibria exist provided that the tender rate is below $\gamma$. We now turn to describing the equilibria in greater detail.

Theorem 6 Suppose (i) monetary policy is tight but the tender rate is below the long's participation ceiling, $\theta$, (ii) it is possible for the short to cover his position in the tender, (iii) the tender is competitive, and (iv) the short is relatively small. ${ }^{15}$ If the tender rate is below $\gamma$, there is a unique equilibrium in pure strategies where: (a) each player demands a quantity equal to the size of his collateral in the tender; and (b) the tender is oversubscribed and there is always a short squeeze in the secondary market.

Here, since the short is a relatively small bank, irrespective of the short's bid, the long can implement a squeeze by demanding $c_{L}$ units in the tender. Moreover, the long finds it profitable to do so irrespective of the short's bid, since the tender rate is below $\gamma$. Therefore, the long bids for a quantity equal to his collateral. The certainty of a squeeze, means that the short does the same. In contrast, when the tender rate is above $\gamma$, it would not be worthwhile for the long to demand $c_{L}$ if the short demands $c_{S}$, since the tender rate is now too high given the amount of units the long can implement a squeeze on.

Next, we consider the case that the short can cover for sure by demanding $c_{S}$ in the tender; i.e., the short is a relatively large bank.

\footnotetext{
${ }^{14}$ By these statements we mean: (i) $R_{T} \in\left(R_{0}, \theta\right)$, (ii) $z_{0}<\min \left(c_{S}, Q\right.$ ), and (iii) $z_{0}+c_{L}>Q$.

${ }^{15}$ By these statements we mean: (i) $R_{T} \in\left(R_{0}, \theta\right)$, (ii) $z_{0}<\min \left(c_{S}, Q\right.$ ), (iii) $z_{0}+c_{L}>Q$, and (iv) $z_{0}>\lambda c_{S}$.
} 
Theorem 7 Suppose (i) monetary policy is tight but the tender rate is below the long's participation ceiling, $\theta$, (ii) it is possible for the short to cover his position in the tender, (iii) the tender is competitive, and (iv) the short is relatively large. ${ }^{16}$ Suppose also that $z_{0} / Q<\left(R_{T}-R_{0}\right) /\left(R_{H}-R_{0}\right)$. The following is an equilibrium:

$$
b_{S}^{*}= \begin{cases}z_{0} & \text { with probability } p_{S} \\ \frac{z_{0}}{Q-z_{0}} c_{L} & \text { with probability } 1-p_{S},\end{cases}
$$

and

$$
b_{L}^{*}= \begin{cases}0 & \text { with probability } p_{L} \\ c_{L} & \text { with probability } 1-p_{L}\end{cases}
$$

where

$$
p_{L}=\frac{\left(R_{H}-R_{T}\right)\left(Q-z_{0}\right)}{\left(c_{L}+z_{0}\right)\left(R_{T}-R_{0}\right)+\left(Q-z_{0}\right)\left(R_{H}-R_{T}\right)},
$$

and

$$
p_{S}=\frac{\left(R_{T}-R_{0}\right)\left(Q-z_{0}\right)\left(c_{L}+z_{0}\right)}{\left(R_{H}-R_{T}\right) z_{0}\left(c_{L}+z_{0}-Q\right)} .
$$

A simple implication of this mixed strategy result is that the post-tender interbank rate will be more variable, across tenders, in an economy where the short tends to be relatively large as compared to in an economy where the short tends to be relatively small. Furthermore, in the economy where the short is relatively large, whether or not there is a short squeeze is highly uncertain. This degree of uncertainty is in sharp contrast to our previous result, where we had unique pure strategy equilibria (for $R_{T}<\gamma$ ).

Having gone through the various cases, a general picture is starting to emerge. First, we see that when the tender is competitive and the tender rate is below the participation ceiling, oversubscription and short squeezes are equilibrium phenomena that tend to come together when market power is large. The other main features of the general picture are summarized here:

Proposition 3 Suppose (i) monetary policy is tight, and (ii) it is possible for the short to cover his position in the tender. ${ }^{17}$ In equilibrium: (1) The total quantity demanded in the tender, as well as the quantity demanded by the long and by the short in the tender separately, is increasing in the long's collateral and decreasing in the tender size. (2) The probability and size of a short squeeze in the secondary market is increasing in the long's collateral and decreasing in the tender size and tender rate.

This proposition contains essentially the same conclusion as when the short cannot cover in the tender due to insufficient collateral. This also illustrates that the central bank has at least three instruments in a fixed rate tender by which it can influence the tender outcome and the incidence of a squeeze in the secondary market; namely, the tender size, tender rate, and admissible collateral. To the extent that a squeeze is undesirable, our results show how to use these instruments to simultaneously maintain the aim of

\footnotetext{
${ }^{16}$ By these statements we mean: (i) $R_{T} \in(\gamma, \theta)$, (ii) $z_{0}<\min \left(c_{S}, Q\right.$ ), (iii) $z_{0}+c_{L}>Q$ and (iv) $z_{0}<\lambda c_{S}$.

${ }^{17}$ By these statements we mean: (i) $R_{T} \in\left(R_{0}, \theta\right)$, and (ii) $z_{0}<\min \left(c_{S}, Q\right)$.
} 
monetary policy and reduce squeezes. In particular, when the central bank is running a tight monetary policy, by increasing the tender size, the central bank can reduce (or even eliminate) short squeezes without worrying about too much liquidity coming into the market. This is for the simple reason that when the tender size becomes very large, the long player will no longer try to implement a short squeeze - instead he does not participate in the tender.

This also illustrates a major difference between how fixed rate tenders operate under loose and tight monetary policies. As seen in the previous section, under a loose monetary policy, any attempt to eliminate short squeezes by holding very large tenders, will result in huge amounts of liquidity being injected in the banking system, which may be undesirable. In contrast, under a tight monetary policy, when tenders are extremely large, players actually reveal their true liquidity needs in the tender. As an interesting example, in the 1990's, Finland held fixed rate tenders where they gave participating banks exactly what the banks asked for. This worked well in Finland, perhaps because monetary policy was tight, in preparation for joining the monetary union.

\section{Discussion, Extensions, and Concluding Remarks}

In this paper, we have shown that the possibility of a short squeeze in the interbank market can have significant impact on equilibrium behavior in fixed rate tenders. By itself, a tender is a strikingly simple mechanism, but we have seen that adding the secondary market reveals some interesting and important features. The possibility of short squeezing in the secondary market as a result of asymmetric initial positions of the players and pro-rata rationing in the tender might induce players to submit non-trivial bids in the tender. For example, bidders may demand positive amounts even if the tender rate is higher than the competitive rate. They may even demand so much that the tender becomes oversubscribed. Furthemore, the potential for short squeezing may lead to mixed equilibria in some important cases, where the occurrence of a short squeeze is uncertain.

Our analysis implies that there are at least three instruments that a central bank (as an auctioneer in the tender) can use to influence the extent to which there is a short squeeze after the tender. The first is the tender rate. When the tender rate is below the competitive rate, banks bid as much as they can, given their collateral. When the tender rate is "just above" the competitive rate, banks still bid as much as they can. The short does so in order to minimize a short squeeze, and the long does so to maximize a short squeeze. When the tender rate is "intermediate", players use mixed strategies; and when the tender rate is above some ceiling, the long player drops out and the short demands just what he needs to cover. These results are a consequence of the tradeoff faced by the long between borrowing many units in the tender above the competitive market rate, on the one hand, and lending fewer units to the short in the secondary market at an even higher rate, on the other hand.

The second instrument available to the central bank is the tender size, i.e., the amount of liquidity, channeled into the banking system through the tender. The size and likelihood of a short squeeze tends to soften as the tender size increases. There are two related reasons. First, the short player is allocated more as a result of pro-rata rationing. Second, the long 
needs to buy more units in the tender to squeeze on the same amount of units afterwards, hence the marginal value to the long of winning a unit in the tender falls. More formally, in our model, there is a tender size threshold, beyond which there is no short squeeze.

With respect to tender size, the major difference between our model and fixed rate tenders in practice is that the tender size is often not known by bidders in advance. This supply uncertainty can be of two distinct types. First, it could be completely exogenous, meaning that the bids made by banks in the tender do not affect the amount the bank is willing to sell. For example, the central bank can fix the tender size in advance without informing participating banks. This type of supply uncertainty should not change the major thrust of our results, since our players are risk-neutral. However, exogenous supply uncertainty raises some interesting issues, particularly where supply can turn out to be too small for the short to cover, or turn out to be sufficiently large for the short to cover. We leave this for further research.

Second, supply uncertainty can be endogenous, meaning that the bids made in the tender influcence how much the central bank decides to lend. As an example, consider a fixed rate tender where bidders receive what they ask for. Here, by design, there is never rationing. This eliminates short squeezes provided that the tender rate is above the competitive rate, as shown in Theorem 4. This is intuitive since, as we have expanded on in the paper, rationing and short squeezes tend to go hand in hand. Hence, short squeezing can be reduced by the introduction of endogeneous supply uncertainty. However, a drawback with this endogenous supply mechanism is that if the tender rate is below the competitive rate, demand would be insatiable. So it would not work so well in a period of rising expectations, where the tender rate is lagging behind the market rate. With insatiable demand, it is difficult to imagine that the central bank would not turn to rationing. In this case, short squeezing would reappear.

The third instrument available to the central bank that we have identified is collateral. The central bank may reduce or increase the size of allowable collateral by several methods. It may change the types of collateral allowed to be used in repo operations or introduce haircuts for particular types of collateral. For the sake of argument, suppose that this affects all players in equal proportions, say $\alpha$. This can either increase or decrease the extent of short squeezes. To see this in the context of our model, suppose first that initially $z_{0}+c_{L}<Q$ and $c_{S}>z_{0}$. In this case, there is no short squeeze. After a reduction in collateral, the situation could be $\alpha\left(z_{0}+c_{L}\right)<Q$ and $\alpha c_{S}<z_{0}$. Now the short has insufficient collateral to cover, and so there will be a short squeeze. Suppose second that the initial situation is $z_{0}+c_{L}>Q$ and $c_{S}>z_{0}$. In this scenario, we have shown that there may be short squeezes in equilibrium, depending upon the tender rate. After collateral is reduced, the situation could be $\alpha\left(z_{0}+c_{L}\right)<Q$ and $\alpha c_{S}>z_{0}$. Now, there will not be a short squeeze. These two simple examples illustrates the precariousness of using collateral restrictions as a tool in controlling the outcome of the tender and the interbank market. This is also true when we consider that different banks can be affected differently by changes to the admissible collateral. For example, if smaller banks generally hold collateral of lower quality, then if the short is small, collateral restrictions would tend to increase the extent of short squeezes. In contrast, if the short is large, collateral restrictions would work the opposite way. 
Finally, we briefly discuss a fourth instrument, which we have not touched on in our paper so far, that a central bank can use to influence the incidence of short squeezes; namely, the timing of the announcement of the tender results. This can allow the central bank to adjust the "hardness" of the collateral constraint faced by bidders. In this paper, we have assumed that the collateral constraint is hard, in the sense that bidders cannot demand more than what they have collateral for. This could be enforced in practice if the central bank has an up to date record of all bidders collateral. But if not, bidders could make bids in excess of their collateral in the tender and gamble on a small allotment rate. However, in practice there may be considerable uncertainty regarding the allotment rate, since players may have private information and, possibly as in our model, some players may play mixed strategies. If so, a surprisingly high allotment rate may mean that some aggressive bidders find themselves short of collateral. If there is very little time between the announcement time and the actual transaction time (e.g. the announcement time is late in the day), uncertainty about the allotment rate may help enforce a hard collateral constraint, assuming that the central bank can punish players who are short collateral and unable to complete the repo. The more time players have between the announcement of the result and the transaction time, the softer is the collateral constraint since the players have more time to obtain extra collateral if their allotment leaves them short. However, this also opens up the possibility of a squeeze on collateral as well as on liquidity. It may well be the case that squeezes on collateral can be so severe that the very possibility of it means that banks would rarely demand more in the tender than what they could cover with the collateral that they have on hand. If so, we would be back in our hard collateral constraint model.

Overall, this paper suggests that the behavior of players in fixed rate tenders and the consequences of such behavior are not as simple as they appear at first glance. Here, the complicating factor is the potential for a short squeeze in the secondary market. We have shown that this may lead to overbidding in the tender. The low allotment rates in the ECB's fixed rate tenders in 1999-6/2000 shows that bidding in the auction can be extremely strong. For example, on 31 May 2000, the allotment rate was only $0.87 \%$ (ECB Monthly Bulletin, July 2000, p. 37). This severe overbidding could have been due to rising interest rate expectations, but it could also have been augmented by a fear among banks of having to satisfy their liquidity needs predominantly in the secondary market. Some smaller banks apparently complained about having to go to the interbank markets because they were not able to overbid enough to get the liquidity they needed in the tender, due to not having sufficient eligible collateral. However, what is important for our analysis is not that short squeezes do happen, but that they may happen. Short squeezing is fundamentally a manifestation of a liquidity shortfall overall (the tender is too small given the needs of the banking sector) or an imperfectly competitive interbank market. The spikes in interbank rates observed from time to time suggests that interbank markets can be less than competitive and therefore that short squeezing needs to be taken seriously. However, ultimately this is an empirical question, which would be important to address in future research. 


\section{Appendix: Proofs}

\section{Proof of Theorem 1}

Since $R_{T}<R_{0}$, it is straightforward that each player maximises his payoff by maximising the number of units he is allocated. So the unique equilibrium is for each player to bid an amount equal to his collateral. Hence, the short covers his initial position if and only if if $z_{0} \leq \lambda c_{S}$. payoffs in all cases follow directly from (1) and (2).

\section{Proof of Proposition 1}

Observe first that by Theorems 2 and 3 , the short always bids $c_{S}$. So any variation in the total amount demanded in the tender arises from variations in the amount bid by the long. Let $B=c_{S}+b_{L}^{*}$ denote the total amount demanded in the tender in equilibrium. Now, from inspecting the expression for the participation ceiling in Theorem 3 , $\theta_{c}$, we see that (i) $\theta_{c}$ increases with $c_{L}$ (since $\frac{\partial \theta_{c}}{\partial c_{L}}=-\frac{R_{H}-R_{0}}{Q}>0$ ); and (ii) $\theta_{c}$ is decreasing in $Q$ (since $\left.\frac{\partial \theta_{c}}{\partial Q}=-\frac{\left(c_{L}+c_{S}\right)\left(R_{H}-R_{0}\right)}{Q^{2}}<0\right)$; furthermore, (iii) $\theta_{c}=0$ when $Q=C\left(\equiv c_{S}+c_{L}\right)$. Now, by Theorem 3, (i) immediately establishes that the long's bid, and therefore $B$, is decreasing in $c_{L}$. Furthermore, if $Q \leq z_{0}$, Theorem 2 shows that $B=C$. Additionally, (ii) and (iii) imply that there is $Q\left(R_{T}\right) \in\left(z_{0}, C\right)$ for which $\theta_{c}=R_{T}$ and $\theta_{c}>(<) R_{T}$ whenever $Q>(<) Q\left(R_{T}\right)$. Hence, Theorem 3 implies that $B=C$ for $Q<Q\left(R_{T}\right)$ and $c_{S}$ for $Q \geq Q\left(R_{T}\right)$. This establishes claim (1). To prove (2), observe that the number of units on which there is a squeeze in the secondary market is equivalent to the (absolute value of) the short's position after the tender. (2) then follows as an immediate implication of (1) and the observation that the short always bids $c_{S}$.

\section{Proof of Theorem 4}

Since $z_{0}+c_{L} \leq Q$, the short can cover his position with certainty by demanding $z_{0}$ units in the tender. It follows that it is optimal for the short to demand $b_{S}^{*}=z_{0}$, since $R_{T} \in\left(R_{0}, R_{H}\right)$, irrespective of the long's demand. Given this, the long will not be able to squeeze on any units. Hence, it is optimal for the long to demand $b_{L}^{*}=0$. This also shows uniqueness, undersubscription, and the absence of short squeezing.

\section{Proof of Theorem 5}

We start by observing that since $R_{T}<R_{H}$, in equilibrium the short will demand at least $z_{0}$, since this is what the short needs to cover his position. Moreover, in equilibrium, the short will demand at most $\bar{b}_{S}=\min \left[c_{S}, \hat{b}_{S}\right]$, where $\hat{b}_{S}$ satisfies $\hat{b}_{S} Q /\left(\hat{b}_{S}+c_{L}\right)=z_{0}$, since demanding more than this is either impossible or will result in the short for sure obtaining more than he needs to cover his position. Suppose therefore that the short submits $b_{S} \in\left[z_{0}, \bar{b}_{S}\right]$. We will show that there is $\theta\left(b_{S}\right)$ such that if $R_{T}>\theta\left(b_{S}\right)$ then the long will choose to bid $b_{L}=0$.

Define $\underline{b}_{L}\left(b_{S}\right)$ to be such that $b_{S} Q /\left(b_{L}\left(b_{S}\right)+b_{S}\right)=z_{0}$. Thus, if the long demands $b_{L} \in\left(0, \underline{b}_{L}\left(b_{S}\right)\right]$, the short will cover his position for sure and the long's payoff per unit that he wins is $R_{T}-R_{H}<0$. Hence the long either demands 0 or $b_{L} \in\left(\underline{b_{L}}\left(b_{S}\right), c_{L}\right]$. If the 
long demands the latter, there is a short squeeze for sure, and the long's payoff is

$$
\pi_{L}^{*}\left(b_{L}\right)=\left(z_{0}-\frac{b_{S}}{b_{S}+b_{L}} Q\right) R_{H}+\left(y_{L}-z_{0}+Q\right) R_{0}-\frac{b_{L}}{b_{S}+b_{L}} Q R_{T} .
$$

Note that

$$
\frac{\partial \pi_{L}^{*}}{\partial b_{L}}=\frac{b_{S} Q\left(R_{H}-R_{T}\right)}{\left(b_{L}+b_{S}\right)^{2}}>0,
$$

so the optimal $b_{L} \in\left(\underline{b_{L}}\left(b_{S}\right), c_{L}\right]$ is $c_{L}$. If the long demands zero, his payoff is

$$
\pi_{L}^{P}=y_{L} R_{0}
$$

Hence, comparing $\pi_{L}^{*}\left(c_{L}\right)$ and $\pi_{L}^{P}$, we see that the the long strictly prefers to demand zero if and only if

$$
R_{T}>\frac{R_{0}\left(Q-z_{0}\right)+z_{0} R_{H}}{Q}-\frac{b_{S}}{c_{L} Q}\left(R_{H}-R_{0}\right)\left(Q-z_{0}\right) \equiv \theta\left(b_{S}\right)
$$

and the long strictly prefers to demand $c_{L}$ if and only if $R_{T}<\theta\left(b_{S}\right)$. It is easy to see that $\theta\left(b_{S}\right)$ is decreasing in $b_{S}$. Hence, we have established that the long bids zero whenever $R_{T}>\theta \equiv \theta\left(z_{0}\right)$. It follows immediately that when $R_{T}>\theta$, the short demands $z_{0}$, implying that there is undersubscription and no short squeezing.

\section{Proof of Proposition 2}

The proof follows immediately from inspecting the first derivatives of $\theta$ with respect to $c_{L}$, $z_{0}$, and $Q$ respectively.

\section{Proof of Lemma 1}

By the proof of Theorem 5, in a pure strategy equilibrium the long either demands $b_{L}=0$ or $b_{L}=c_{L}$.

Define $\gamma$ as

$$
\gamma= \begin{cases}\frac{R_{0}\left(Q-z_{0}\right)+z_{0} R_{H}}{Q}-\frac{c_{S}}{c_{L} Q}\left(R_{H}-R_{0}\right)\left(Q-z_{0}\right) & \text { if } z_{0}>\lambda c_{S} \\ R_{0} & \text { otherwise. }\end{cases}
$$

It is easy to check that $\gamma<\theta$.

Suppose $R_{T} \in(\gamma, \theta)$. Consider first the case that the long bids $b_{L}=0$. The best response for the short is $b_{S}=z_{0}$, since this is what he needs to cover his short position. But then, by the proof of Theorem 5 , the long would do better by bidding $b_{L}=c_{L}$, since this allows him to squeeze and $R_{T}<\theta$. Thus, the strategy $b_{L}=0$ is not an equilibrium strategy.

Consider next the case that $b_{L}=c_{L}$. Suppose first that $\lambda c_{S}>z_{0}$ (note that in this case $\lambda=R_{0}$ ). In this case, the best response for the short is to bid $\hat{b}_{S}$ (see the proof of Theorem 5). But then there would be no short squeezing, and so the long would be better off by demanding $b_{L}=0$. Suppose next that $\lambda c_{S}<z_{0}$. The best response for the short is then to demand $b_{S}=c_{S}$, since this minimizes the short squeeze. Now, comparing the 
definition of $\gamma$ with the definition of $\theta\left(b_{S}\right)$ in the proof of Theorem 5 , we see that $\gamma=\theta\left(c_{S}\right)$. Hence, by the proof of Theorem 5 , it follows that the long would do better by demanding $b_{L}=0$, since $R_{T}>\gamma$. Thus $b_{L}=c_{L}$ is not an equilibrium strategy. This also establishes that there are no pure strategy equilibria if $R_{T} \in(\gamma, \theta)$.

The existence of a mixed equilibrium follows from Glicksberg's Theorem on the existence of mixed-strategy equilibria when payoffs are continuous (see, e.g., Fudenberg and Tirole (1992), page 35, Theorem 1.3). This observation concludes the proof.

\section{Proof of Theorem 6}

Since $R_{T}<\gamma=\theta\left(c_{S}\right)$, the proof of Theorem 5 shows that in any equilibrium, the long demands $b_{L}=c_{L}$. It follows that the short optimizes by demanding $b_{S}=c_{S}$, since this minimizes the amount on which he is squeezed (since $z_{0}>\lambda c_{S}$ ). Hence the unique equilibrium is that $b_{L}=c_{L}$ and $b_{S}=c_{S}$. The tender is oversubscribed, since $c_{S}+c_{L}>Q$. There is always a short squeeze, since $z_{0}>\lambda c_{S}$.

\section{Proof of Theorem 7}

Let the strategies be as given in the Theorem. Then the payoffs of the long and the short are respectively (by direct calculation)

$$
\pi_{L}^{*}=y_{L} R_{0}
$$

and

$$
\pi_{S}^{*}=\frac{z_{0}\left(Q R_{0}\left(R_{H}-R_{T}\right)+c_{L} R_{H}\left(R_{T}-R_{0}\right)+\left(R_{T}^{2}-R_{0} R_{H}\right) z_{0}\right)}{c_{L}\left(R_{0}-R_{T}\right)+Q\left(R_{T}-R_{H}\right)+\left(R_{0}+R_{H}-2 R_{T}\right) z_{0}} .
$$

Moreover, keeping the strategy of the other player fixed, direct calculation also confirms that the short and the long get these payoffs by playing either of the strategies they are mixing over in the proposed equilibrium.

We will first show that $b_{L}^{*}$ is a best response to $b_{S}^{*}$, which we now take as given. Define $\underline{b_{L}}$ to be such that $\frac{z_{0}}{b_{L}+z_{0}} Q=z_{0}$. If the long deviates from $b_{L}^{*}$ by demanding $b_{L} \in\left(0, \underline{b_{L}}\right]$, his payoff is strictly less than $\pi_{L}^{*}$, since he wins positive amount in the tender, but without being able to implement a short squeeze.

Consider next that $b_{L} \in\left(\underline{b_{L}}, c_{L}\right)$. The long's payoff becomes

$\pi_{L}\left(b_{L}\right)=\pi_{L}^{*}+p_{S}\left(\left(z_{0}-\frac{z_{0} Q}{b_{L}+z_{0}}\right) R_{H}+\left(Q-z_{0}\right) R_{0}-\frac{b_{L}}{b_{L}+z_{0}} Q R_{T}\right)+\left(1-p_{S}\right) \frac{b_{L}}{b_{L}+\frac{z_{0} c_{L}}{Q-z_{0}}} Q\left(R_{0}-R_{T}\right)$.

After substituting in the expression for $p_{S}$ (in the statement of the Theorem) and simplifying, the difference between $\pi_{L}\left(b_{L}\right)$ and $\pi_{L}^{*}$ becomes

$$
\begin{gathered}
\pi_{L}\left(b_{L}\right)-\pi_{L}^{*}=\frac{\left(b_{L}-c_{L}\right)\left(R_{0}-R_{T}\right)\left(Q-z_{0}\right)}{\left(R_{H}-R_{T}\right)\left(b_{L}+z_{0}\right)\left(c_{L}-Q+z_{0}\right)\left(b_{L}\left(Q-z_{0}\right)+c_{L} z_{0}\right)} \\
\quad \times\left\{\left(R_{0}-R_{H}\right)\left(Q-z_{0}\right) z_{0}\left(c_{L}+z_{0}\right)\right.
\end{gathered}
$$




$$
\left.+b_{L}\left(-\left(Q-z_{0}\right)\left(Q\left(R_{H}-R_{T}\right)-z_{0}\left(R_{H}-R_{0}\right)\right)+c_{L}\left(Q\left(R_{0}-R_{T}\right)+\left(R_{H}-R_{0}\right) z_{0}\right)\right)\right\}
$$

The first term is positive. Simple algebra establishes that the sum in the second term is negative, since $z_{0}<Q \frac{R_{T}-R_{0}}{R_{H}-R_{0}}$. Hence, the long would be strictly worse off by any deviation from the proposed strategy, $b_{S}^{*}$.

Consider now the strategy of the short, given the strategy of the long, $b_{L}^{*}$. If the short deviates by bidding $b_{S} \in\left(\frac{z_{0}}{Q-z_{0}} c_{L}, c_{S}\right)$, he will always cover his short position, but he is allocated $q_{S}>z_{0}$, so he loses $\left(q_{S}-z_{0}\right)\left(R_{0}-R_{T}\right)$ in comparison with playing just $b_{S}=\frac{z_{0}}{Q-z_{0}}$ or $z_{0}$. Moreover, bidding less than $z_{0}$ is strictly dominated by bidding $z_{0}$, since this will lead to a short squeeze for sure.

Next, consider the case $b_{S} \in\left(z_{0}, \frac{z_{0}}{Q-z_{0}} c_{L}\right)$. Then the short's payoff is given by

$$
\pi_{S}\left(b_{S}\right)=p_{L}\left(\left(b_{S}-z_{0}\right) R_{0}-b_{S} R_{T}\right)+\left(1-p_{L}\right)\left(-\frac{b_{S}}{c_{L}+b_{S}} Q R_{T}-\left(z_{0}-\frac{b_{S}}{c_{L}+b_{S}}\right) Q R_{H}\right) .
$$

After substituting in the expression for $p_{L}$ (in the statement of the Theorem), and simplifying, we get

$$
\pi_{S}^{*}-\pi_{S}\left(b_{S}\right)=\frac{\left(R_{0}-R_{T}\right)\left(R_{T}-R_{H}\right)\left(b_{S}-z_{0}\right)\left(\left(c_{L}+b_{S}\right) z_{0}-Q b_{S}\right)}{\left(c_{L}+b_{S}\right)\left(\left(c_{L}+z_{0}\right)\left(R_{0}-R_{T}\right)+\left(R_{T}-R_{H}\right)\left(Q-z_{0}\right)\right)},
$$

which is less than zero, since the denominator is negative and the numerator is positive (since $b_{S}<\frac{z_{0}}{Q-z_{0}} c_{L}$ ). Hence, the short is strictly worse off by deviating from the proposed strategy. This establishes a Nash equilibrium and completes the proof.

\section{Proof of Proposition 3}

It follows from Theorems $4,5,6$, and 7 that the behaviour of the short and the long depends on the value of $R_{T}$ relative to the parameters $\gamma$ and $\theta$. Note that $R_{0} \leq \gamma<\theta<R_{H}$, i.e. the interval $\left[R_{0}, R_{H}\right]$ is partitioned into three regions, where the equilibrium outcomes are quite different. First, when $R_{T} \in\left(\theta, R_{H}\right]$, the total demanded quantity is $B_{0}=b_{L}+b_{S}=0+z_{0}=z_{0}$ and there is no short squeeze. Second, when $R_{T} \in(\gamma, \theta)$, there exist mixed equilibria, where $B_{1}=b_{L}+b_{S} \in\left[z_{0}, c_{S}+c_{L}\right]$ for sure. Also the expected value of $B_{1}$ is in $\left(z_{0}, c_{S}+c_{L}\right)$. Here, a probability is positive, but less than one. Third, when $R_{T} \in\left[R_{0}, \gamma\right)$, the total demanded quantity is $B_{2}=b_{L}+b_{S}=c_{L}+c_{S}>Q>z_{0}$, and short squeezing happens for sure. Observe that $\theta$ is increasing in $c_{L}$ and decreasing in $Q$ (Proposition 2). Observation that similar calculations confirm this holds also for $\gamma$ concludes the proof.

\section{References}

1. Bester, H., 1987, "The Role of Collateral in Credit Markets with Imperfect Information", European Economic Review, 31, 887-899.

2. Bester, H., 1994, "The Role of Collateral in a Model of Debt Renegotiation", Journal of Money, Credit, and Banking, 26, 72-86. 
3. Biais, B., Hartmann, P., and Manna, M., 2000, "The Microstructure of the Euro Money Market", working paper.

4. Breitung, J., and D. Nautz, 2000, "How German Banks Bid in the ECB's Repo Auctions: Evidence from a Panel Data Analysis", working paper, Humboldt University at Berlin.

5. Catalão Lopes, M., 2000, "Financing in the Eurosystem: Fixed versus Variable Rate Tenders", working paper, Bank of Portugal and IST-Economia e Gestão.

6. Chatterjea, A., and R. A. Jarrow, 1998, "Market Manipulation, Price Bubbles, and a Model of the U.S. Treasury Securities Auction", Journal of Financial and Quantitative Analysis, 33, 255-89.

7. Cooper, D. J., and R. G. Donaldson, 1998, "A Strategic Analysis of Corners and Squeezes" Journal of Financial and Quantitative Analysis, 33, 117-37.

8. Ehrhart, K.-M., 2000, "Repo Auctions: Experimental Investigation of Fixed Rate Tenders", working paper, University of Karlsruhe.

9. European Central Bank Monthly Bulletin, July 2000.

10. Fudenberg, D., and J. Tirole, 1992, Game Theory, MIT Press.

11. Hamilton, J.D., 1996, "The Daily Market for Federal Funds," Journal of Political Economy, 104, 26-56.

12. Holmstrom, B., and J. Tirole, 1997, "Financial Intermediation, Loanable Funds, and the Real Sector", Quarterly Journal of Economics, 112, 663-691.

13. Jarrow, R. A., 1992, "Market Manipulation, Bubbles, Corners, and Short Squeezes" Journal of Financial and Quantitative Analysis, 27, 311-336.

14. Jarrow, R. A., 1994, "Derivative Security Markets, Market Manipulation, and Option Pricing Theory" Journal of Financial and Quantitative Analysis, 29, 241-261.

15. Kumar, P., and D. J. Seppi, 1992, "Manipulation with 'Cash Settlement'", Journal of Finance, 47, 1485-1502.

16. Nyborg, K. G., and I. A. Strebulaev, 2001, "Multiple Unit Auctions and Short Squeezes", working paper, London Business School.

17. Rock, K., 1986, "Why New Issues Are Underpriced", Journal of Financial Economics, 15, 187-212. 